\title{
Temperature Fluctuations in a Landfill in Response to Periodic Changes in Surface and Tide-Driven Groundwater Temperatures
}

\author{
Ninghu Su ${ }^{1}$, Kartik Venkatraman ${ }^{2^{*}}$ and Nanjappa Ashwath ${ }^{3}$ \\ ${ }^{1}$ School of Earth and Environmental Sciences, James Cook University, Cairns, QLD 4870, Australia \\ ${ }^{2}$ East Gippsland Shire Council, 273 Main Street, Bairnsdale, Victoria 3875, Australia \\ ${ }^{3}$ School of Medical and Applied Science, CQUniversity, Rockhampton, QLD 4702, Australia
}

*Corresponding author: Kartik Venkatraman, East Gippsland Shire Council, 273 Main Street, Bairnsdale, Victoria 3875 , Australia, Tel: 03 5153 9500; E-mail: kartikv@egipps.vic.gov.au

Received date: April 29, 2014; Accepted date: June 17, 2014; Published date: June 25, 2014

Copyright: (c) 2014 Venkatraman K, et al. This is an open-access article distributed under the terms of the Creative Commons Attribution License, which permits unrestricted use, distribution, and reproduction in any medium, provided the original author and source are credited.

\begin{abstract}
In Australia, the concentration of population along the coastal regions has resulted in the construction of landfills near the coastal regions. The wastes buried in these unlined landfills are therefore exposed to tidal influence, often resulting in the dispersion of organic and inorganic pollutants to the surrounding environment. In a project cosponsored by the Rockhampton Regional Council, a number of processes at a landfill site situated in the flood plains of the Fitzroy River are being investigated. The processes include those in terms of multiphase flow consisting of gas (methane), solute (measured as salts, via $\mathrm{EC}$ and $\mathrm{pH}$ ) and water in a porous media.

In this paper we analyse temperature changes in groundwater and porous media of the landfill which is subject to periodic surface and tide-driven temperatures. The heat equation is solved, subject to two periodic boundary conditions $(B C)$ : the top $B C$ is a periodic surface temperature due to the change in air temperature, and bottom $B C$ is a periodic function to account for the changes in groundwater temperature induced by tides. The methods can be used to locate key parameters and variables of concern in the porous media, and to forecast their variability with time, using publicly available air temperature and tide data.
\end{abstract}

Keywords: Phytocapping; Soil temperature; Groundwater temperature; Landfill

\section{Introduction}

The waste sector in Australia has advanced over the last decade due to developments in technology. This has introduced Alternative Waste Technologies (AWT) and Energy from Waste (EfW) technologies. In addition, greater emphasis has been placed over recycling, waste diversion and landfill remediation strategies. Despite problems associated with landfills, they are still being built due to their lower capital cost and being the easiest means of disposing waste globally and in Australia [1,2]. Landfilling is particularly common in regional areas due to low population density and high cost of transporting wastes to cities where other methods of disposing or recycling waste have been well established. Due to increased generation of wastes, Local Governments who own and run most of the landfills have concerns over environmental problems arising from these landfills. Landfills built prior to 1993 in Australia do not have liners [3] and have become a major threat to the environment [4]. At present, more than 600 landfills are in operation in Australia [5,6] and most of the small and medium sized landfills in regional Australia still operate with bare minimum infrastructure, despite making landfill capping mandatory for all landfills; big or small.

Local Governments are responsible for municipal solid waste management; including collection, storage, treatment and disposal. In Australia, it is mandatory to obtain a license to operate and maintain landfills. These licenses specify types of waste to be accepted, means of managing environmental pollution (dust, air, odour and water), landfill design criteria and post closure management and monitoring. Every Local Government organisation that owns and operates a landfill is required to abide by the license condition to reduce environmental impacts. However, ongoing maintenance and operating costs of landfills are significantly higher for small and medium sized councils (population $<200,000)$ than for large councils. Some regional councils in Australia operate more than 10 landfills/waste tranfer stations (WTS) and maintainance of these landfills is becoming difficult and expensive.

Operational and closure costs of landfills have escalated due to increasing environmental awareness and stringent regulations of the Environmental Protection Authority (EPA). The most popular practice in Australia is the use of a compacted clay cap [7]. Costs of construction, operation and maintenance of clay caps, as specified by State Governments, are very high depending on size of landfill and local availability of clay material. Studies in the past demonstrate that many medium and small types of council have not budgeted for landfill capping. In most cases waste disposal fees and charges do not include landfill capping expenses. Furthermore, mandatory monitoring of landfill's environmental performance, and managing integrity of clay caps for up to 30 years would create another difficulty for many councils.

Lakes Creek Road Landfill was constructed in 1981 and is the largest (45 ha) landfill currently operated and managed by the Rockhampton Regional Council. It is located within the Fitzroy River flood plain, at approximately $1 \mathrm{~km}$ from the Fitzroy River. The landfill site is located 
Citation: Ninghu S, Kartik V, Nanjappa A (2014) Temperature Fluctuations in a Landfill in Response to Periodic Changes in Surface and TideDriven Groundwater Temperatures. Int J Waste Resources 4: 148. doi:10.4172/2252-5211.1000148

Page 2 of 8

adjacent to residential properties to the North of Rockhampton City, a water body to the West, and a mangrove dominated creek to the South and East. Once filled, this landfill site will have to be capped as per the Department of Environment and Heritage Protection (DEHP); previously known as the Department of Environment and Resource Management (DERM) guidelines.

Rockhampton is situated on the Tropic of Capricorn $\left(23.5^{\circ} \mathrm{S}\right)$. It receives rain mostly between November to March with a winter rainfall received during June and September. Rockhampton's average rainfall is $780 \mathrm{~mm} \mathrm{yr}^{-1}$ (average of 47 years) with a Potential Evapotranspiration (PET) rate of $1632 \mathrm{~mm} \mathrm{yr}^{-1}$. The daytime temperature ranges between $32^{\circ} \mathrm{C}(\max )$ to $22^{\circ} \mathrm{C}(\min )$ during summer (wet season) and $23^{\circ} \mathrm{C}(\max )$ to $9^{\circ} \mathrm{C}$ ( $\mathrm{min}$ ) during winter (dry season).

The landfill site is entirely unique from other landfill sites in Queensland due to its topographic conditions, tropical climate, where PET is greater than annual rainfall by 2 fold, rainfall distribution, depth of the ground water (approx. 3.8 to $4 \mathrm{~m}$ from the surface of daily cover, depth of the buried waste ( 5 to $6 \mathrm{~m}$ ) which is influenced by tidal fluctuations. Variation in the depth of groundwater table is greatly influenced by the distance of that site from the river [8].

In Australia, coastal zones are heavily urbanised. As a result many landfills in have been constructed in mangrove habitats making it even more harmful to the surrounding environment. It is therefore important to understand the complex nature of groundwater containing nutrients and heavy metals [9]. The fluctuation in ground water levels due to tidal flux is critical due to its impact on the buried waste and methane emission into the atmosphere. Tidal fluctuations can affect groundwater behaviour up to a distance ranging from $21 \mathrm{~m}$ (lateral) [9-11] up to $1 \mathrm{~km}$ (lateral) [12] with a certain time lag [11,13-15].

Tidal fluctuations are important as they may be linked to ground water discharge [14]. Groundwater may contain heavy metals and ion from landfills and reclaimed land [9]. Piezometers [16] and level sensor (PS21000) manufactured by Green Span (Australia) were used in study to understand the influence of tides on the groundwater.

\section{Experimental setup}

The tidal fluctuations were monitored as part of a research conducted on Phytocapping; an alternative capping technology to reduce waste percolation into buried waste. Piezometer wells were installed at the site - 3 wells x 2 replications. One set of 3 wells were installed near the trial plot at the eastern end and a second set of 3 wells were installed $100 \mathrm{~m}$ away from the plots (towards the Fitzroy River). Piezometers at each location were installed at $2 \mathrm{~m}, 5 \mathrm{~m}$ and $9 \mathrm{~m}$ depths. During the installation process, the ground surface was drilled to the desired depth (e.g. $2 \mathrm{~m}$, $5 \mathrm{~m}, 9 \mathrm{~m}$ ) and piezometer wells were installed (Figure 1).

While drilling the $9 \mathrm{~m}$ piezometer well, soil samples were collected from various depths to determine moisture content and composition of soil material (Table 1). Samples were collected to a depth of $9 \mathrm{~m}$ at $0.5 \mathrm{~m}$ increments (Figure 2).

Each piezometer well was capped at the top end and was insulated with a screen or a mesh cloth at the bottom end for protection from clogging. Then, wells were insulated by sand and bentonite [17]. After installation, the wells were covered and protected by a metallic tube with a lid and a lock (Figure 3) to protect wells from external environment. During installation, a temperature sensor was also attached to the bottom of the well to observe variations in water temperature. Temperature was recorded using the smart logger (Figure 3) which was used for sap flow measurements.

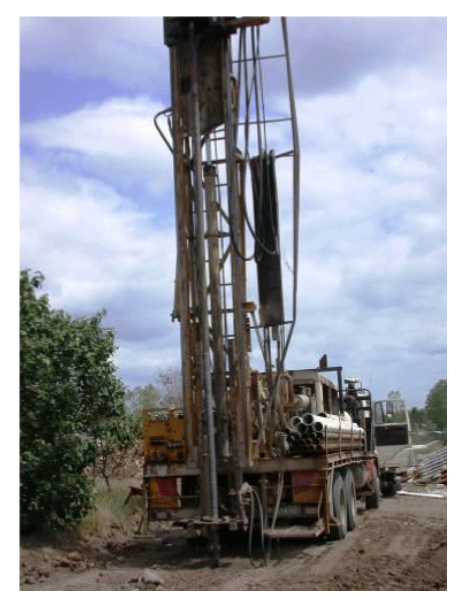

Figure 1: Drilling of piezometer wells. 
Citation: Ninghu S, Kartik V, Nanjappa A (2014) Temperature Fluctuations in a Landfill in Response to Periodic Changes in Surface and TideDriven Groundwater Temperatures. Int J Waste Resources 4: 148. doi:10.4172/2252-5211.1000148

Page 3 of 8

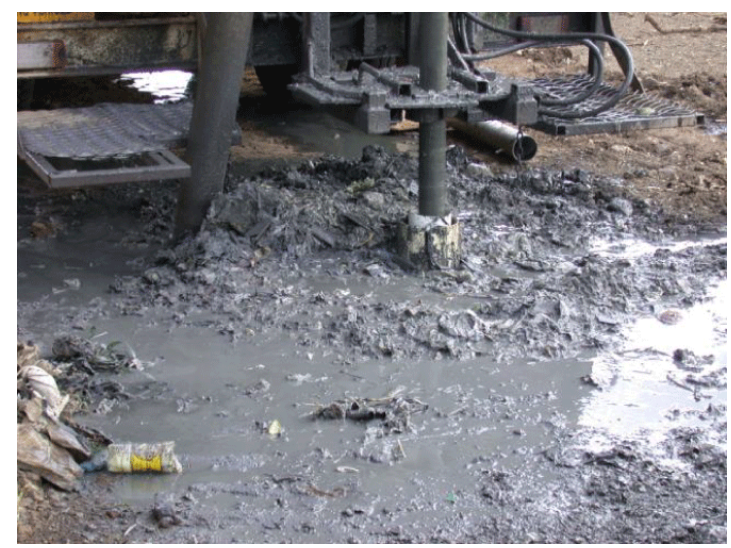

Figure 2: Wet waste samples from $6 \mathrm{~m}$ depth.

\begin{tabular}{|l|l|l|}
\hline Depth $(\mathbf{m})$ & Plot 1 & Plot 2 \\
\hline 1 & soil + stones & soil + stones \\
\hline 2 & soil + dry waste + Stones & soil + dry waste + stones \\
\hline 3 & soil + stones + dry waste & soil + stones + dry waste \\
\hline 4 & soil + dry waste & soil + dry waste \\
\hline 5 & wet waste & wet waste \\
\hline 6 & wet waste & wet waste \\
\hline 7 & wet waste & wet waste \\
\hline 8 & wet waste & clay water $(7.8 \mathrm{~m})$ \\
\hline 9 & clay water $(8.5 \mathrm{~m})$ & clay water \\
\hline
\end{tabular}

Table 1: Composition of the landfill material at various depths.

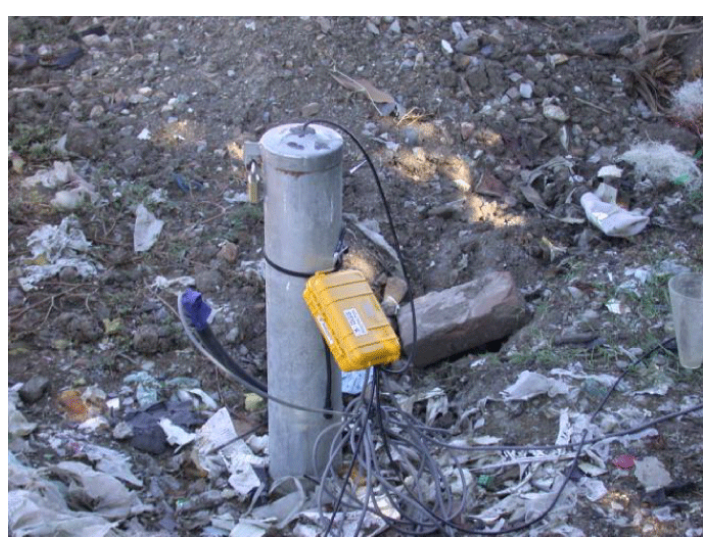

Figure 3: Piezometer tube completely protected with metal casing.

\section{Meteorological Data}

Monthly micro-climatic data was gathered from the Bureau of Meteorology (BOM) site at Rockhampton and from a weather station that was installed at the landfill site. Hourly, daily, monthly and yearly temperature, relative humidity, wind direction, radiation, evaporation wind 
Citation: Ninghu S, Kartik V, Nanjappa A (2014) Temperature Fluctuations in a Landfill in Response to Periodic Changes in Surface and Tide-

velocity, rainfall, rainfall duration and rainfall intensity data were obtained for the duration of the study. This data was required to evaluate the performance of the phytocaps for methane emission and species transpiration rates and canopy rainfall interception potential. This data was also used in simulating the site water balance using HYDRUS 1D. Tidal information was obtained from the Queensland Maritime Safety (QMS) Office for Fitzroy River.

\section{Results and Discussion}

It is well known that the soil temperature is influenced both by the fluctuating air temperature and by the tidal temperatures. The measured temperatures of the air and the soil are shown in Figure 4.

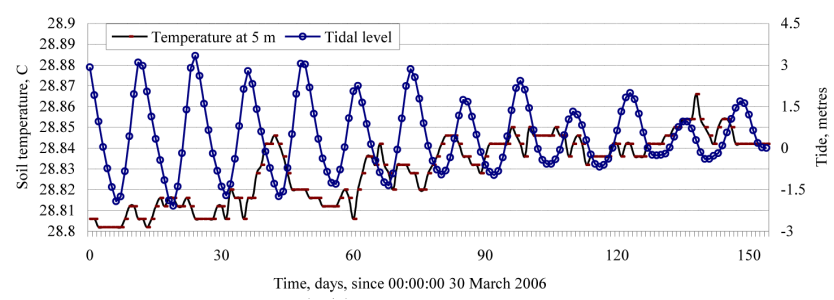

Figure 4: Soil temperature changes in response to changes in tidal height.

It is evident from Figures 4 and 5 that the changes in soil temperature do not strictly follow neither the air temperature nor the tidal heights (and hence the temperature). A combination of these might influence the soil temperature in the landfill. Thus, the combinations of air temperature and the ground water temperature influence the soil temperature under the landfill. As a consequence, we need to incorporate the two effects in the analysis shown below, which in mathematical terms, can be interpreted as two periodic boundary conditions.

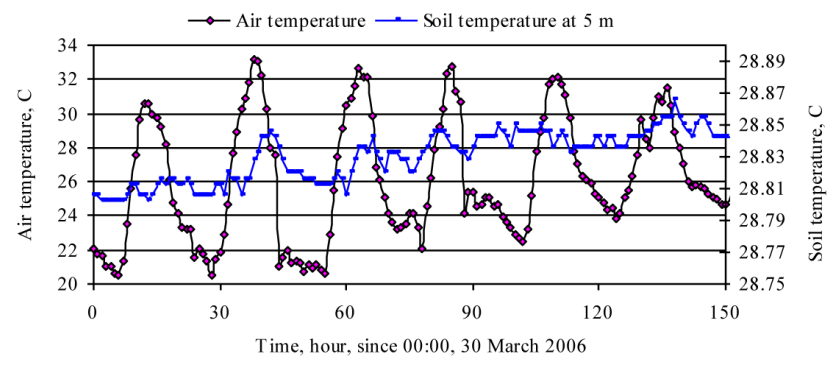

Figure 5: Effect of air temperature on the soil temperature.

\section{Mathematical Formulation for Heat Transfer in Soils}

When the groundwater temperature is affected both by the fluctuating air temperature from the surface and tidal temperature from the bottom, the temperature in the groundwater will be an integrated response to both the air temperature and tidal temperature accordingly. For such a problem, the mathematical formulation becomes a classic mixed time-dependent initial and boundary problem, which can be written as [18],

$$
\begin{array}{ll}
\frac{\partial T}{\partial t}=\frac{\partial}{\partial z}\left(k \frac{\partial T}{\partial z}\right) & \\
T(z, t)=\phi_{1}(t) & z=0 \\
T(z, t)=\phi_{2}(t) & z=D \\
T(z, t)=f(z) & t=0
\end{array}
$$

Where $\quad \mathrm{T}$ is the temperature $\left({ }^{\circ} \mathrm{C}\right)$;

$\mathrm{z}$ is the vertical space coordinates $(\mathrm{L}$, e.g., $\mathrm{cm}$ );

$\mathrm{t}$ is time;

$f(z)$ is the initial temperature distribution with depth; 
Citation: Ninghu S, Kartik V, Nanjappa A (2014) Temperature Fluctuations in a Landfill in Response to Periodic Changes in Surface and Tide-

$\mathrm{k}$ is the thermal diffusivity (usually in units of $\mathrm{cm}^{2} / \mathrm{h}$ ), and

$k=\frac{\lambda}{\rho c}$

With $\lambda$ the thermal conductivity (in units of $\mathrm{m} / \mathrm{h}$ );

$\rho$ the gravimetric density of soil particles $\left(\mathrm{kg} / \mathrm{m}^{3}\right)$;

$\mathrm{c}$ the specific heat capacity of the soil $(\mathrm{kJ} / \mathrm{kgK})$.

Normally, the term $\rho c$ is called the volumetric heat capacity $\left(\mathrm{kJ} / \mathrm{m}^{3} \mathrm{~K}\right)$. Marshall et al. [19] suggested that a weighted mean of the volumetric hear capacity, $\overline{\rho c}$, is used to account for the constituency of the soil, i.e,

$$
\overline{\rho c}=\sum_{i=1}^{n} \theta_{i}(p c)_{i}
$$

Where $i$ the counter of constituents, $i=1,2, \ldots n$, and $\Theta_{i}$ is the content of constituent $i$ expressed as a volumetric fractions of the soil.

$\varphi_{1}(t)$ and $\varphi_{2}(t)$ are respectively the time-dependent functions on the surface such as air temperature, and tide temperature, and both of which can be conveniently expressed as periodic functions. The air temperature can be written as

$$
\varphi_{1}(t)=A_{1} \sin \left(\omega_{1} t-\phi_{1}\right)
$$

and the tidal temperature can be written as the following [20], Eq. (34),due to tidal movement,

$\varphi_{2}(t)=A_{2} \cos \left[\omega_{2} t+m \sin \left(\omega_{m} t-\phi_{2}\right)\right]$

Where $A_{1}$ and $A_{2}$ are the amplitudes of air and tide, respectively;

$\omega_{1}$ and $\omega_{2}$ are the frequencies of air and tide, respectively:

$\omega_{\mathrm{m}}$ and $\mathrm{m}$ is the frequency of tidal modulation and modulation index, respectively;

$\omega 1=\frac{2 \pi}{p 1}$

$\omega 2=\frac{2 \pi}{p 2}$

$\phi_{1}$ and $\phi_{2}$ are the phase shifts of air and tide temperatures, respectively; and

$\mathrm{p}_{1}$ and $\mathrm{p}_{2}$ the wavelengths of air and tide temperatures, respectively.

Equation (1) and its initial and boundary conditions are clear, and we solve it following the work of Carslaw and Jaeger who regard $\mathrm{T}$ as a linear combination of two separate components [18] i.e.,

$$
\mathrm{T}=\mathrm{u}+\mathrm{w}
$$

with

$$
\begin{array}{ll}
\frac{\partial u}{\partial t}=\frac{\partial}{\partial z}\left(k \frac{\partial u}{\partial z}\right) & \quad 0<z<D \\
u(z, t)=T_{a} & z=0, z=D \\
u(z, t)=f(z) & t=0
\end{array}
$$

and

$\frac{\partial u}{\partial t}=\frac{\partial}{\partial z}\left(k \frac{\partial u}{\partial z}\right) \quad 0<z<D$

$\mathrm{w}(\mathrm{z}, \mathrm{t})=\phi 1(\mathrm{t}) \mathrm{z}=0$

$\mathrm{w}(\mathrm{z}, \mathrm{t})=\phi 1(\mathrm{t}) \mathrm{z}=\mathrm{D}$

$\mathrm{w}(\mathrm{z}, \mathrm{t})=0 \mathrm{t}=0$

Carslaw and Jaeger presented closed-form solutions of Eq. (1) using by expanding the fundamental solution in a sine series. However, a visual analysis of Carslaw and Jaeger's solution shows that a cosine series expansion is physically realistic and appropriate [18].With the cosine series expansion, the solution of Eq. (1) subject to (2) to (4) is given as 
Citation: Ninghu S, Kartik V, Nanjappa A (2014) Temperature Fluctuations in a Landfill in Response to Periodic Changes in Surface and Tide-

Page 6 of 8

$$
T(z, t)=\frac{2}{D} \sum_{i=1}^{n} \exp \left[-\left(\frac{n \pi}{D}\right)^{2} k t\right] \cos \left(\frac{n \pi z}{D}\right)\left[\int_{0}^{D} f\left(z^{\prime}\right) \cos \left(\frac{n \pi z^{\prime}}{D}\right) d z^{\prime}+\frac{n k \pi}{D} \int_{0}^{t} \exp \left[\left(\frac{n \pi}{D}\right)^{2} k \tau\right]\left[A_{1} \sin \left(\omega_{1} \tau-\varphi_{1}\right)-(-1)^{n} A_{2} \cos \left(\omega_{2} \tau-\varphi_{2}\right)\right] d \tau\right]
$$

Equation (20) is a complete solution, and can be simplified for applications. In practice, a few terms (one or two terms) will be sufficient to approximate the full solution. Here we use only one term as demonstration,

$$
T(z, t)=\frac{2}{D} \exp \left[-\left(\frac{\pi}{D}\right)^{2} k t\right] \cos \left(\frac{\pi z}{D}\right)\left[\int_{0}^{D} f\left(z^{\prime}\right) \cos \left(\frac{\pi z^{\prime}}{D}\right) d z^{\prime}+\frac{k \pi}{D} \int_{0}^{t} \exp \left[\left(\frac{\pi}{D}\right)^{2} k \tau\right]\left[A_{1} \sin \left(\omega_{1} \tau\right)+A_{2} \cos \left(\omega_{2} \tau\right)\right] d \tau\right]
$$

The further integration of Eq. (19) or (20) can be easily completed when the initial distribution of temperature, $\mathrm{f}(\mathrm{z})$, is specified. Under the natural conditions, any temperature profile regarded as an initial distribution is a periodic temperature at a particular time, i.e., the initial temperature is also a function of a periodic function. We use a cosine function, to represent the initial value, i.e,

$$
f(z)=A_{0} \cos \left(\frac{\pi z}{D}+\varphi_{i}\right)+B_{0}
$$

with $\mathrm{A}_{\mathrm{o}}$ the amplitude, $\phi_{\mathrm{i}}$ the phase shift, and $\mathrm{B}_{\mathrm{o}}$ a constant accounting for the background value.

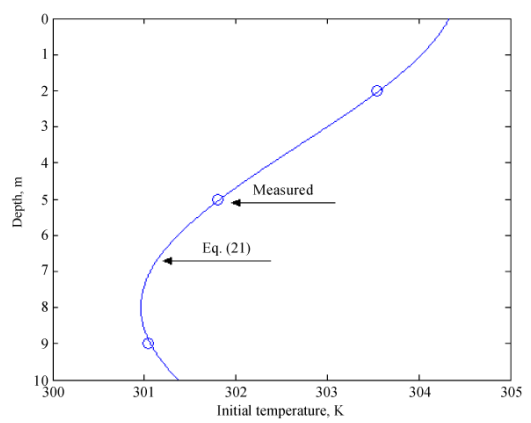

Figure 6: The initial temperature (00:00, 30 March 2006) function and measured values.

It can be seen from Figure 6 that Eq. (21) yields a perfect fitting to the data. Fitting Eq. (21) fitted to the data yields $A_{o}=-1.738(K)$, $\phi \mathrm{i}=-1.738(\mathrm{~K})$, and $\mathrm{B}_{\mathrm{o}}=302.7(\mathrm{~K})$.

With Eq. (21), Eq. (20) can be fully completed for two cases: $\omega \neq \pi$ and $\omega=\pi$, and the case for $\omega=\pi$ is physically relevant. In the case of $\omega=\pi$,we have Gradshteyn [21],

$$
T(z, t)=\frac{\cos (a z)}{\exp (b t)} \llbracket K_{0}+\frac{2 k \pi}{D^{2}}\left\{\begin{array}{l}
K_{1}\left\{\exp (b t)\left[b \sin \left(\omega_{1} t\right)-\omega_{1} \cos \left(\omega_{1} t\right)\right]+\omega_{1}\right\}+ \\
K_{2}\left\{\exp (b t)\left[b \cos \left(\omega_{2} t\right)-\omega_{2} \sin \left(\omega_{2} t\right)\right]-b\right\}
\end{array}\right\} \rrbracket
$$

with

$$
\begin{aligned}
a= & \frac{\pi}{D} \\
\mathrm{~b} & =\mathrm{a}^{2} \mathrm{k} \\
K_{0} & =A_{0}\left[\cos \left(\varphi_{i}\right)+\frac{\sin \left(2 a D+\varphi_{i}\right)-\sin \left(\varphi_{i}\right)}{2 a D}\right]-\frac{2 B 0 \sin (a D)}{a D} \\
K_{1} & =\frac{A_{1}}{b^{2}+\omega_{1}^{2}} \\
K_{2} & =\frac{A 2}{b^{2}+\omega_{2}^{2}}
\end{aligned}
$$

Equation (22) is complex, and it describes a periodic temperature across the soil subject to the two periodic boundary conditions. Once all the values of the parameters are given, Eq. (22) can be used for predictive and design purposes. 
Citation: Ninghu S, Kartik V, Nanjappa A (2014) Temperature Fluctuations in a Landfill in Response to Periodic Changes in Surface and Tide-

\section{Application of the Model}

In the following section, we briefly illustrate the use of the approach presented above in simulating the changes in soil temperature in response to the temperatures of the air and the tide-induce groundwater. The simulated monthly soil temperatures are shown in Figure 6 for different depths.

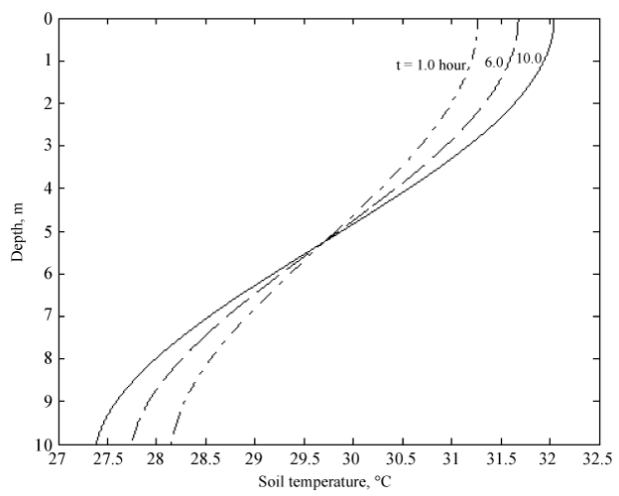

Figure 7: Changes in soil temperature with depth (A) and time (B).
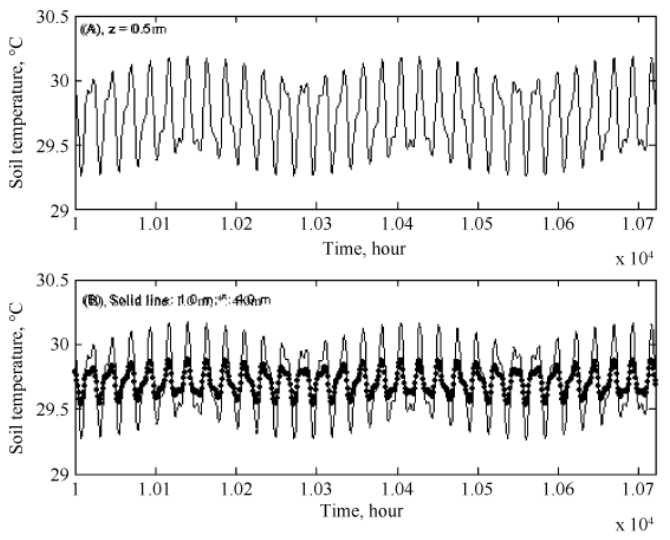

Figure 8: Changes in soil temperature on a monthly scale with a daily resolution.

It can be seen from the above figures that with the procedures described above the complex periodic variations in soil temperature can be simulated satisfactorily.

When simulating the soil temperature using the above methods, two points should be made clear:

[1] An extended "warming up" time is required for the solution to an attain equilibrium state, and the time indicated in Figure 6 is about 10,000 hours;

[2] An average soil temperature, a number equivalent to $B_{0}$, is added to the solution to obtain the above Figures 7 and 8 .

\section{Conclusion}

The above analysis shows that the variation in soil temperature in response to two periodic boundary conditions is very complex. The closedform solution is very useful for analysing the changes of soil temperature with depth and time as illustrated.

Most of the data used in the illustration are from measurements, and one of the key parameters for the soil is the thermal conductivity, $\mathrm{k}$, which was calibrated using the data since its measurement is impossible given the nature of the wastes.

Further work is needed to acquire various types of data, particularly the thermal conductivity, $\mathrm{k}$ (a value of 0.005 used here) to reveal temperature patterns at different layers. Further analyses can also be carried out to use Eq. (22) for predictive and design purposes. 
Citation: Ninghu S, Kartik V, Nanjappa A (2014) Temperature Fluctuations in a Landfill in Response to Periodic Changes in Surface and TideDriven Groundwater Temperatures. Int J Waste Resources 4: 148. doi:10.4172/2252-5211.1000148

Page 8 of 8

\section{Acknowledgement}

This research was funded by the Rockhampton City Council (RCC) via Phytolink Pty Ltd. and proudly supported by the Queensland Government's Growing the Smart State PhD Funding Program and may be used to assist public policy development. The State of Queensland accepts no responsibility for decisions or actions resulting from any information supplied. The views and information contained in the research do not necessarily represent the views or opinion of the Queensland Government and carry no endorsement by the Queensland Government.

We are grateful to Mr. Craig Dunglison: Rockhampton City Council (RCC), Mr. Lindsay Best (RCC), Mr. Richard Yeates (Phytolink Aust), Professor David Midmore, Central Queensland University (CQU), Dr. Ninghu Su, James Cook University (JCU), Dr. Bodapati Naidu, Department of Natural Resources and Mines (DNR), Dr. Surya Bhattarai (CQU), Roshan Subedi (CQU), Mr. Ajay Sharma (CQU) and all other staff and colleagues at CQU and ICT International, Australia for their guidance and support.

\section{References}

1. Scott J, Beydoun D, Amal R, Low G, Cattle J (2005) Landfill management, leachate generation and leach testing of solid wastes in Australia and overseas. Critical Reviews in Environmental Science and Technology 35: 239-332.

2. Izzo RLS, Guedes V, Tarazona CF, Almedia LC, Mahler CF (2009) New equipment for measuring gas flows in sanitary landfills. In: 12th International Waste Management and Landfill Symposium.

3. Friends of Earth (2000) Friends of Earth Citizens Guide to Municipal Landfills. In Friends of Earth.

4. CSIRO (2001) Australia State of the Environment. CSIRO Melbourne.

5. Bateman S (2005) National Landfill Survey. In: Landfill Brisbane.

6. Johnston A (2009) Landfill survey fills a hole.

7. EPA (2005) Environmental Protection Agency.

8. Kim K, Seong H, Kim T, Park K, Woo N, et al. (2006) Tidal effects on variations of fresh-saltwater interface and groundwater flow in a multilayered coastal aquifer on a volcanic island (Jeju island, Korea). Journal of Hydrology 330: 525-542.

9. Suh J, Brown PL, Birch GF (2003) Hydrological characteristics and importance of natural and anthropogenic influences on soil and groundwater in reclaimed land adjacent to Port Jackson Sydney Australia. Marine and Freshwater Research 54: 767-779.

10. Cheng J, Chen C, Ji M (2004) Determination of aquifer roof extending under the sea from variable density flow modelling of groundwater response to tidal loading: case study of the Jahe River Basin Shandong Province China. Hydrogeology Journal 12: 408-423.

11. Richard WG, Robert JG, Brad K (2005) Tidal influence upon groundwater fluctuations in a fresh water tidal mitigation wetland South-eastern Virginia. Salt Lake City Utah.

12. Momii K, Shoji J, Nakagawa K (2005) Observations and modelling of sea water intrusion for a small limestone island aquifer. Hydrological Process 19: 3897-3909.

13. Neilsen P (1990) Tidal dynamics of the water table in beaches. Water Resources Research 26: 2127-2134.

14. Li F, Heine W (2007) Purification of landfill leachate with open channel reverse osmosis membrane module. Australia.

15. Baird AJ, Mason T, Horn DP (1998) Validation of a Couss-inesq model of beach groundwater behavior. Marine Geology 148: 55-69.

16. Lallahem S, Mania J, Hani A, Najjar Y (2004) On the use of neutral networks to evaluate ground water levels in fractured media. Journal of Hydrology 307 : 92-111.

17. Sprecher SW (2000) Installation monitoring wells/piezometer in wetlands. Wetlands Regulatory Assistance Program 1-17.

18. Carslaw HS, Jaeger JC (1959) Conduction of heat in solid. Clarendon.

19. Marshall TJ, Holmes JW, Rose CW (1996) Soil Physics.

20. Su N, Liu F, Anh V (2003) Tides as phase-modulated waves inducing periodic groundwater flow in coastal aquifers overlaying a sloping imperious base. Environmental Modelling \& Software 18: 937-942.

21. Gradshteyn IS, Ryzhik IM (1994) Tables of integrals and series and products. 